\title{
Effect of radial base-plate welds on ULCF capacity of unanchored tank connections
}

\author{
Gary S. Prinz ${ }^{\mathrm{a}, *}$, Alain Nussbaumer ${ }^{\mathrm{b}}$ \\ a Dept. of Civil Engineering, University of Arkansas, Fayetteville, AR 72701, United States \\ b Steel Structures Laboratory (ICOM), Swiss Federal Institute of Technology (EPFL), Switzerland
}

\section{A R T I C L E I N F O}

Article history:

Received 22 October 2013

Accepted 7 August 2014

Available online $\mathrm{xxxx}$

\section{Keywords:}

Ultra low-cycle fatigue

Unanchored liquid storage tanks

Fracture

Earthquake engineering

\begin{abstract}
A B S T R A C T
The base of large steel liquid storage tanks can uplift during severe earthquakes, causing large inelastic rotations at the connection between the tank shell and tank base. While recent experimental studies indicate significantly higher connection rotation capacity than what is specified in the current Eurocode standard (set at 0.2 rad), additional radial base-plate welds (present in some tank connection details due to fabrication methods) have never been considered in tests. This study experimentally investigates the effects of these radial base-plate welds on the fatigue capacity of tank shell-to-base connections during uplift. Twelve tank shell-to-base connection specimens taken from existing tanks throughout Switzerland are tested at rotation ranges greater than the current Eurocode limit (eight specimens with radial welds and four specimens without radial welds). Testing indicates that tank base-plate sections containing radial welds govern the shell-to-base rotation capacity during uplift. The rotation capacity of connections containing radial welds was nearly $30 \%$ lower (on average) than equivalent connections without radial welds. This reduced capacity is directly related to the reduced base-plate ductility created by the radial weld heat affected zone. All connection capacities were far greater than the current Eurocode limit.
\end{abstract}

(c) 2014 Elsevier Ltd. All rights reserved.

\section{Introduction}

Large steel liquid storage tanks are often designed and constructed without attachments or anchors to the supporting foundation. In these tanks, called herein unanchored tanks, the weight of the stored liquid and weight of the tank structure itself are usually sufficient to prevent sliding or complete overturning of the tank during severe earthquakes; however, the possibility still exists for the tank to rock and for the base of the tank to uplift from the foundation.

The process of tank base uplifting can generate large inelastic strains within the base-plate connections [1-5], potentially leading to ultralow-cycle fatigue damage. Current European standards limit the amount of permissible tank-base uplift by limiting the amount of rotation at the connection between the tank base and tank shell. The shell-to-base rotation limit in the current version of Eurocode 8 (EC84 ) is fixed at $0.2 \mathrm{rad}[6]$.

Because large steel liquid storage tanks are typically constructed by welding together much smaller steel plate sections, similar to construction of a patchwork quilt, there are two shell-to-base connection configurations to consider: 1) connections contained within an entire base-plate section having only circumferential welds (welds between the base-plate and shell), and 2) connections at the junction of two base-plate sections having both circumferential

\footnotetext{
* Corresponding author.

E-mail address: prinz@uark.edu (G.S. Prinz).
}

and radial welds (radial welds are created when two adjacent baseplate sections are joined). Fig. 1 shows a typical tank assembly, with the tank base having multiple pentagonal sections near the tank edge, forming a ring for connection of the tank shell. Connections having only circumferential welds have been fatigue tested in two recent studies [7,8]; however, connections with both radial and circumferential welds have not been tested.

Experimental testing of tank shell-to-base connections having only circumferential shell-to-base welds indicate a significant increase in fatigue capacity with increased base-plate ductility [8], and significantly higher rotation capacity than the current EC8-4 limit. Because baseplate ductility has such a strong influence on fatigue performance, potential changes due to the presence of radial welds could have significant effect on fatigue capacity. The performance of tank connections containing radial welds relative to the existing EC8-4 limit is unknown.

This paper expands upon the experimental work in $[7,8]$ by: 1) examining the effects of radial base-plate welds on connection capacity, 2) expanding current experimental data taken from existing tank connections, and 3) creating additional fatigue-life curves for fatigue evaluation of tank connections having radial welds.

The paper begins by describing the experimental investigation to determine the rotation capacity of tank shell-to-base connections under constant range uplift cycles. Included in the description are the test setup, instrumentation, cyclic loading protocol, and detail of test specimens used. Next, fatigue results from the testing are discussed, fatigue-life curves are created, and conclusions regarding connection 


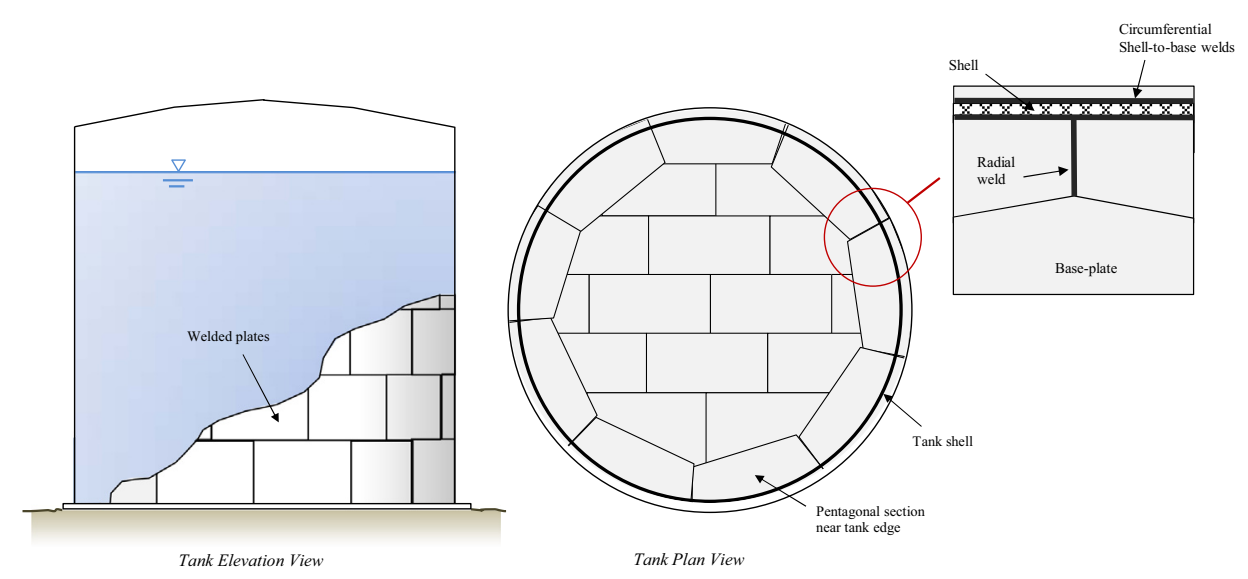

Fig. 1. Typical tank fabrication using multiple steel plates.

capacities are presented. Recommendations for modification of the existing Eurocode limit of 0.2 rad are presented. Two types of specimens are considered in the experimental program, ones having radial baseplate welds and ones without radial welds; the two specimen types are taken from existing tanks from within Switzerland.

\section{Experimental setup and instrumentation}

\subsection{Test overview}

The experimental setup is designed to simulate realistic demands on tank connections during uplift. The test setup uses two actuators (one force controlled and the other displacement controlled) to load the tank connection specimens. Fig. 2 shows the test setup configuration with the vertical (force controlled) actuator applying a constant baseplate tensile force as the horizontal (displacement controlled) actuator applies rotations through the self-leveling frame. Note that the tank connection specimen is rotated $90^{\circ}$ such that the base-plate is parallel with the vertical actuator. To help transfer the base-plate tensile load into the strong floor and prevent plastic hinge formation in the tank shell, a portion of base-plate extending beyond the tank shell is welded to the self-leveling frame (similar to the testing by $[7,8]$ ).

In the test setup, the load and displacement controlled actuators are identical, both having $500 \mathrm{kN}$ load capacity and $150 \mathrm{~mm}$ stroke. Due to this $150 \mathrm{~mm}$ stroke limitation and a chosen peak base-plate rotation range of $0.4 \mathrm{rad}$, the specimen base-plate length had to change from the previous geometries used in $[7,8]$. This test modification is described in detail in the next section.

\subsection{Specimen geometry and material characterization}

Fig. 3(a) shows the specimen geometry; for comparison the geometry used by Prinz and Nussbaumer [8] is shown in Fig. 3(b). The specimens have a base-plate length of $105 \mathrm{~mm}$ (145 mm shorter than the specimens tested in $[7,8]$ ), and base-plate thickness of $12 \mathrm{~mm}$ (compare with $6 \mathrm{~mm}$ in [8]). All other dimensions including base-plate width and

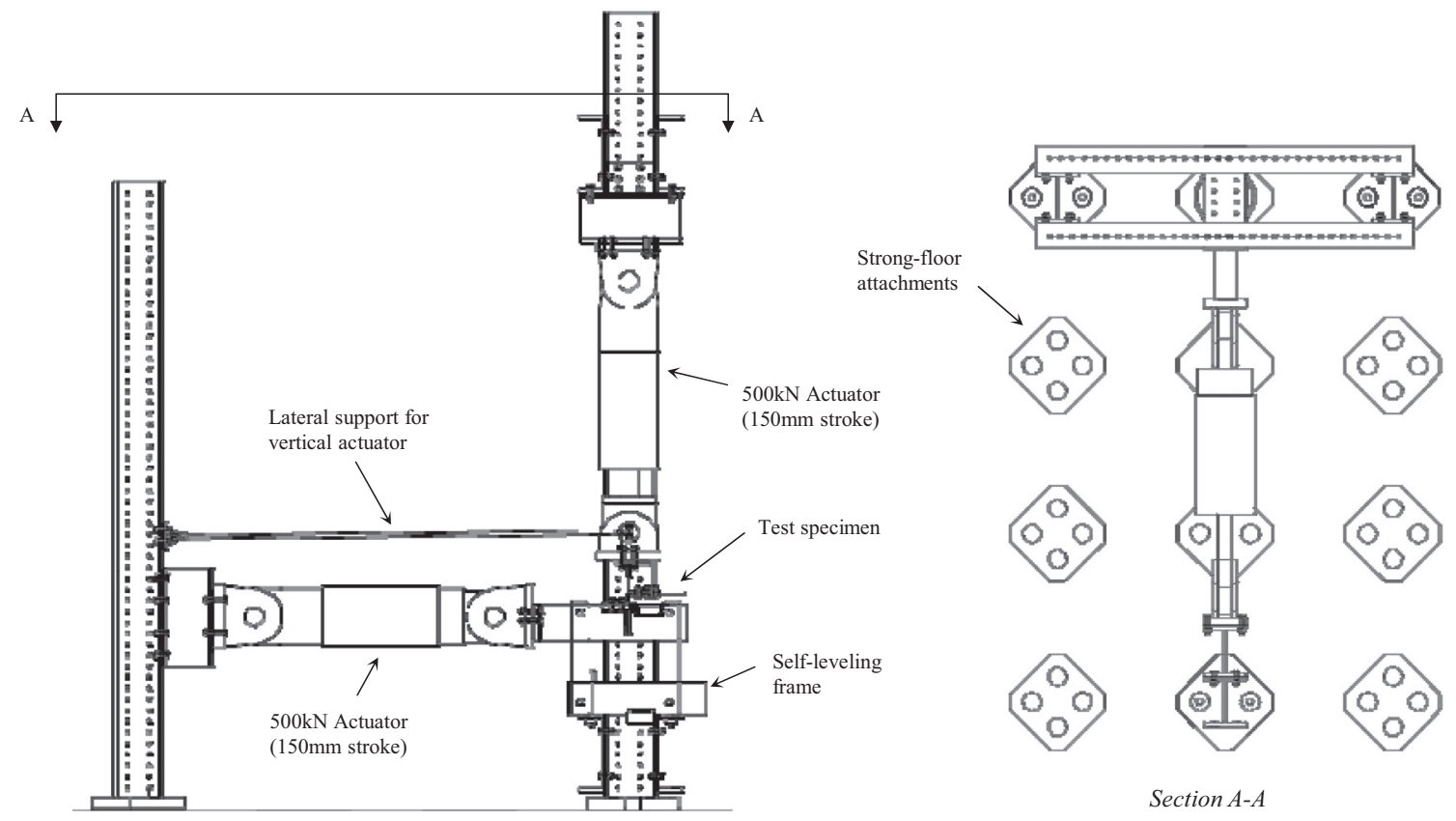

Fig. 2. Experimental test setup. 


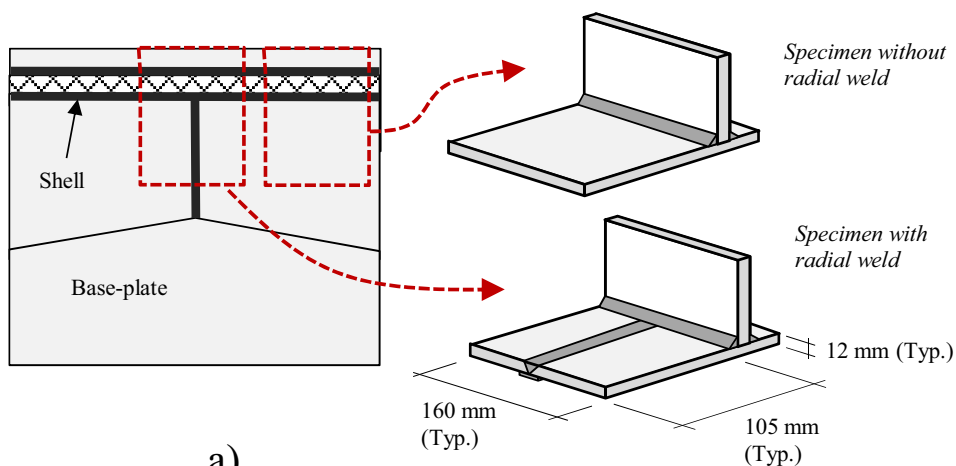

a)
(Typ.)

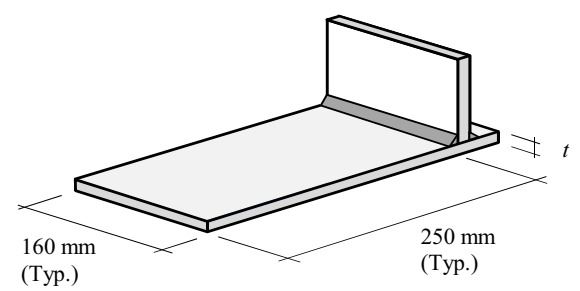

b)

Fig. 3. a) Specimen removal locations and specimen geometry; b) previous geometry used by Cortes et al. [7].

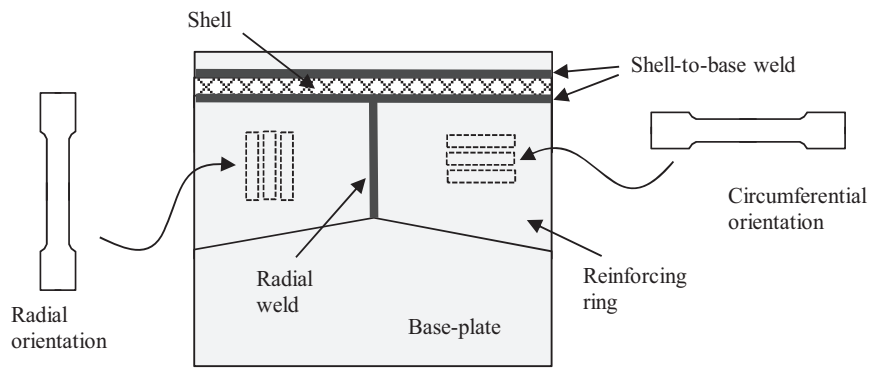

Fig. 4. Individual specimen orientations from removed section of tank.

shell length are consistent between the three experimental studies. All specimens containing radial welds are tested with the weld backingbar (a strip of metal placed under the base-plate during welding) still intact.

To characterize the test specimen material properties, material samples were taken directly from existing tanks within two Swiss tank farms. Several material samples were taken from the base-plates of each tank, representing circumferential and radial base-plate rolled directions (see Fig. 4). Note that all material samples were taken from the thicker reinforcing base-plate ring near the shell-to-base connection. Mean values for yield strength, fracture strain (ductility), and toughness modulus for each tank base-plate location are presented in Table 1.

To characterize the ductility of the radial weld material, additional material samples were removed from the radial welds of test specimens. As was expected, material tests indicate a lower ductility within the weld region $\left(\varepsilon_{f}=0.219\right.$ and 0.289 ). Note that only two valid weld specimens were tested (other weld specimens removed for testing included voids and defects and were unsuitable for characterization). Table 2 presents the individual weld material properties.

Service-load fractures observed in the radial full-penetration welds of several existing tank base-plate samples give cause for concern. Fig. 5 shows the transverse full-penetration weld surface for tanks taken from a tank farm in Sempach, Switzerland. Fractures appear to

Table 1

Average material characteristics for the specimen base-plate base material.

\begin{tabular}{llll}
\hline Tank ID & $\begin{array}{l}\text { Avg. measured } \\
\text { yield }^{a}, \sigma_{y}[\mathrm{MPa}]\end{array}$ & $\begin{array}{l}\text { Avg. fracture } \\
\text { strain, } \varepsilon_{f}\end{array}$ & $\begin{array}{l}\text { Avg. toughness } \\
\text { modulus [MPa] }\end{array}$ \\
\hline S4-E & 371.6 & 0.330 & 156.7 \\
S5-E & 382.7 & 0.343 & 170.1 \\
S5-W & 368.6 & 0.309 & 151.3 \\
S6-E & 362.0 & 0.307 & 150.2 \\
S6-W & 378.2 & 0.338 & 169.6 \\
\hline
\end{tabular}

a Determined from $0.2 \%$ strain offset. originate at the bottom edge of the transverse full-penetration welds (next to where the backing-bar was present) and continue through nearly half of the base-plate thickness. Similar weld fractures were observed in every sample containing radial welds removed from the Swiss tank sites. The geometric flaws that initiate the fractures are presumably unavoidable and repetitive due to limitations on weld cleaning or modification under the tank base.

\subsection{Loading}

All specimens are subjected to constant range rotation cycles to allow direct determination of fatigue life. Two rotation ranges are considered, $0.4 \mathrm{rad}$ and $0.3 \mathrm{rad}$. Table 3 shows the experimental test matrix. In total, thirteen shell to base connections are tested; one specimen leftover from the experimental study by Cortes et al. [7] (modified to have the same geometry as the specimens in this study for verification of negligible size effect on rotation capacity); eight specimens taken from existing tanks having radial base-plate welds; and four specimens taken from existing tanks without radial welds for direct comparison.

\subsection{Instrumentation}

A horizontal linear variable differential transformer (LVDT) and inclinometer are attached locally to each tank specimen to record local uplift displacements and rotations during testing. These local measurements mainly serve as validation of the applied displacements and rotations by the two hydraulic actuators.

\section{Experimental results}

\subsection{Test observations}

Fracture of all tank specimens (excepting Specimen B-2) originated toward the base-plate center, near the radial weld for specimens containing radial welds, and propagated outward toward the plate edges. These fracture initiation locations occurred both at the weld toe and away from the weld toe and weld HAZ. Discussion on fractures occurring at the weld toe and away from the weld toe will be presented later in the Metallographic analysis near transverse and radial weld

Table 2

Material characteristics for the specimen radial weld material.

\begin{tabular}{llll}
\hline Tank ID & $\begin{array}{l}\text { Measured yield }{ }^{\mathrm{a}}, \sigma_{y} \\
{[\mathrm{MPa}]}\end{array}$ & Fracture strain, $\varepsilon_{f}$ & $\begin{array}{l}\text { Toughness } \\
\text { modulus [MPa] }\end{array}$ \\
\hline S4-E & 430 & 0.289 & 136.3 \\
S6-W & 387 & 0.219 & 114.1 \\
\hline
\end{tabular}

a Determined from $0.2 \%$ strain offset. 

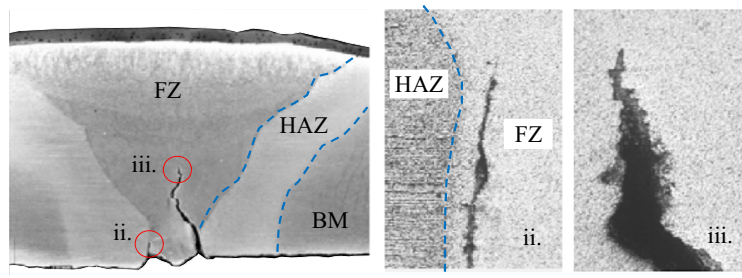

Fig. 5. Example of radial weld fracture and defects observed in existing tank base-plates.

Table 3

Experimental test specimens.

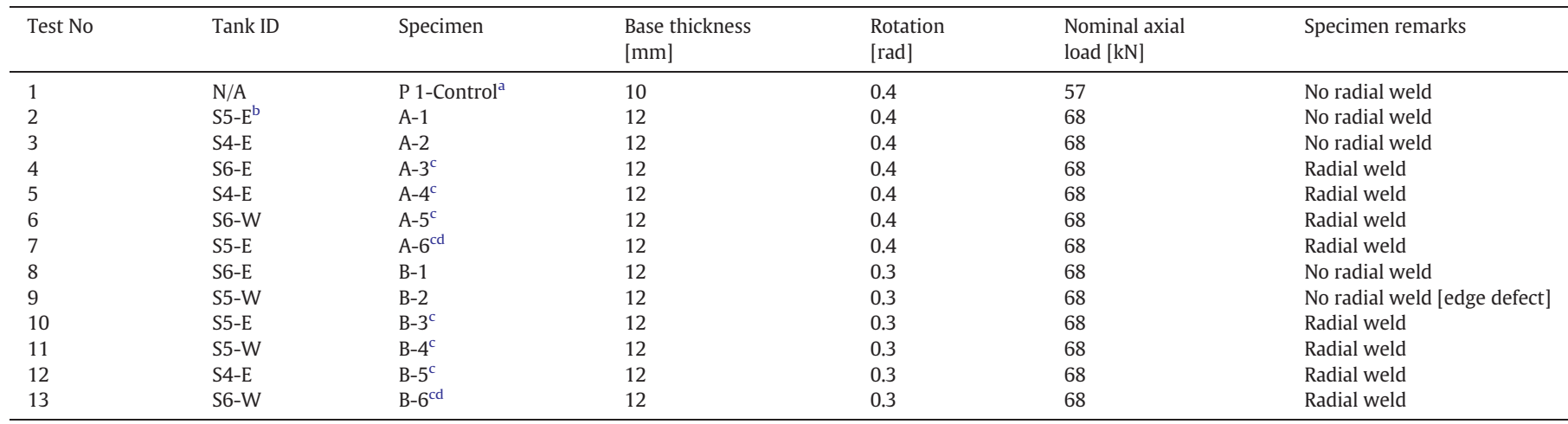

a Control specimen made from Phase-1 materials to ensure negligible effects with updated geometry.

b Specimen taken from Sempach tank farm, tank number 3, east side of tank.

c Specimens containing radial welds.

d Newly fabricated radial welds using Sempach tank materials.

fracture regions section. Fig. 6 shows the initial base-plate fracture within the radial weld region for Specimen B6.

While the fabrication of test specimens was uniform, one specimen (Specimen B-2) was fabricated with an initial defect on one edge of the base-plate. The defect was created during the waterjet cutting process and resembled a small through-thickness notch extending roughly $1 \mathrm{~mm}$ into the edge of the base-plate (see Fig. 7(a)). During testing, it was observed that fracture originated at this edge flaw and ultimately joined with other fractures

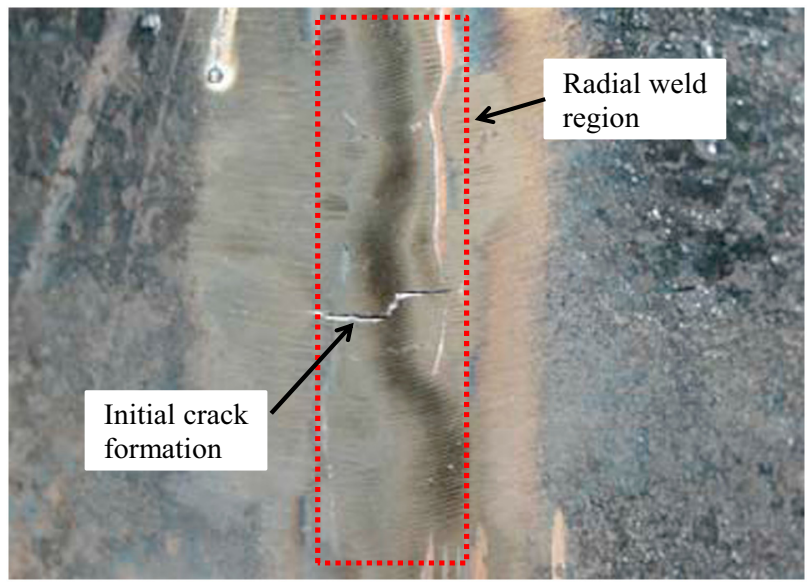

Fig. 6. Initial fracture within the radial weld region on the underside of the Specimen B6 base-plate. that formed near the base-plate center at the weld toe (see Fig. 7(b)). The edge flaw resulted in reduced fatigue life for Specimen B-2.

\subsection{Connection fatigue life}

Before analyzing the fatigue data, it is important to ensure negligible size effects from the new specimen geometry by comparing the control specimen (Specimen P1-Control) with results from previous testing by Cortes et al. [7]. Table 4 presents the test details for each connection specimen (including P1-Control) and the corresponding specimen fatigue life. From Table 4, the $10 \mathrm{~mm}$ thick control specimen, having a $10 \% \sigma_{\mathrm{y}}$ membrane load, reached its fatigue life after 34 cycles at $0.4 \mathrm{rad}$. Similar test specimens tested at $0.4 \mathrm{rad}$ (specimens S3PL7OT10-1 and -2) from Cortes et al., having longer base-plate geometries, failed after 36 to 37 cycles. While the base-plate thickness of the Cortes et al. specimens was $7 \mathrm{~mm}$, the result gives confidence that the reduction in base-plate length has little-to-no effect on determination of connection capacity. This is also verified by finite element simulations in Prinz and Nussbaumer [9] which suggest that damage is localized near the transverse weld.

Fig. 8 presents the fatigue-life curves from the data in Table 4. Note that the specimens with and without radial welds are separated into two curves. The fatigue life curve from Prinz and Nussbaumer [8], having similar base-plate material properties, is plotted for reference. Two types of fatigue-life reductions are evident from the three curves in Fig. 8: 1) a capacity reduction due to base-plate thickness effects (compare $6 \mathrm{~mm}$ plates in [8] with $12 \mathrm{~mm}$ plates in this study, both without radial welds), and 2) a capacity reduction due to the presence of radial welds. The least-squares fit fatigue-life curves for the 
(a)

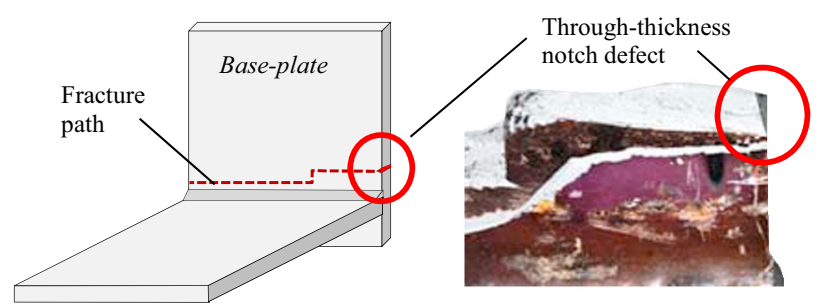

(b)

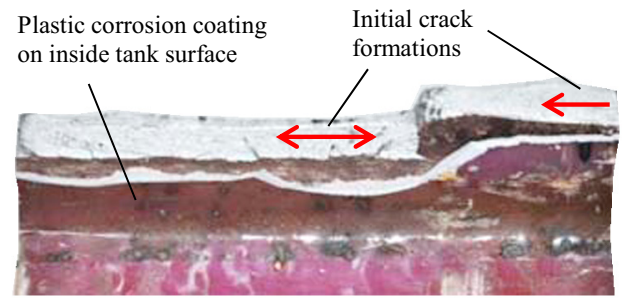

Fig. 7. (a) Initial through-thickness notch defect from fabrication process and (b) final fracture surface.

Table 4

Fatigue life values.

\begin{tabular}{|c|c|c|c|c|c|c|c|}
\hline Test No & Tank ID & Specimen & $\begin{array}{l}\text { Base thickness } \\
{[\mathrm{mm}]}\end{array}$ & $\begin{array}{l}\text { Rotation } \\
\text { [rad] }\end{array}$ & $\begin{array}{l}\text { Nominal axial } \\
\text { load }[\mathrm{kN}]\end{array}$ & $\mathrm{Nf}$ & $\mathrm{m}$ \\
\hline 1 & $\mathrm{~N} / \mathrm{A}$ & P 1-Control ${ }^{\mathrm{a}}$ & 10 & 0.4 & 57 & 34.0 & - \\
\hline 2 & $\mathrm{~S} 5-\mathrm{E}^{\mathrm{b}}$ & A-1 & 12 & 0.4 & 68 & 33.1 & 33.3 \\
\hline 3 & S4-E & A-2 & 12 & 0.4 & 68 & 33.4 & \\
\hline 4 & S6-E & $A-3^{c}$ & 12 & 0.4 & 68 & 17.1 & \\
\hline 5 & S4-E & $A-4^{c}$ & 12 & 0.4 & 68 & 18.1 & 22.7 \\
\hline 6 & S6-W & $A-5^{c}$ & 12 & 0.4 & 68 & 35.4 & \\
\hline 7 & S5-E & $A-6^{c d}$ & 12 & 0.4 & 68 & 20.3 & \\
\hline 8 & S6-E & B-1 & 12 & 0.3 & 68 & 83.4 & 72.8 \\
\hline 9 & S5-W & B-2 & 12 & 0.3 & 68 & $62.2^{\mathrm{e}}$ & \\
\hline 10 & S5-E & $B-3^{c}$ & 12 & 0.3 & 68 & 58.4 & \\
\hline 11 & S5-W & $B-4^{\mathrm{C}}$ & 12 & 0.3 & 68 & 50.0 & 51.5 \\
\hline 12 & S4-E & $B-5^{c}$ & 12 & 0.3 & 68 & 50.2 & \\
\hline 13 & S6-W & $B-6^{\text {cd }}$ & 12 & 0.3 & 68 & 47.2 & \\
\hline
\end{tabular}

a Control specimen made from Phase-1 materials to ensure negligible effects with updated geometry.

b Specimen taken from Sempach tank farm, tank number 3, east side of tank.

c Specimens containing radial welds.

d Newly fabricated radial welds using Sempach tank materials.

e Fracture initiated from a small notch defect on the plate edge and progressed toward cracks forming at the plate center.

specimens with and without radial welds are $\mathrm{N}_{f}{ }^{\psi}=0.652 / \theta^{3.72}$ and $\mathrm{N}_{f}=0.433 / \theta^{2.88}$ respectively.

\subsection{Predictive capability of the Prinz-Nussbaumer fatigue-life equation}

An equation for predicting the fatigue life of tank shell-to-base connections was proposed in [8], dependent only on the applied rotation range and material fracture strain. The equation, presented again in Eq. (1), incorporates a knock-down factor for plates thicker than $6 \mathrm{~mm}$ based on limited testing of $10 \mathrm{~mm}$ and $8 \mathrm{~mm}$ plates. Because

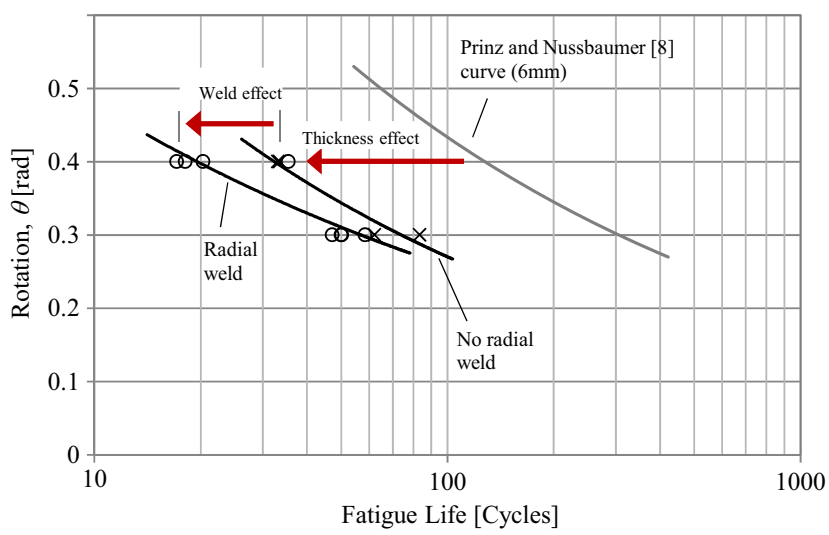

Fig. 8. Fatigue-life curves for $12 \mathrm{~mm}$ test specimens and $6 \mathrm{~mm}$ specimens from [8]. the equation has not been used to evaluate plates thicker than $10 \mathrm{~mm}$, it is worthwhile to compare the predictive capability of Eq. (1) with the $12 \mathrm{~mm}$ specimens tested in this study.

$N_{f}=\left(1.6-\frac{t}{t_{r e f}}\right) \cdot 555 \cdot \varepsilon_{f}^{4.2} \cdot \theta^{\gamma}$

In Eq. (1), $t$ is the base-plate thickness in millimeters, $t_{r e f}$ is the reference base-plate thickness equal to $10 \mathrm{~mm}$, and $\gamma$ is an exponential function dependent on fracture strain equal to $\gamma=-1.97 \varepsilon_{f}{ }^{-0.46}$. For

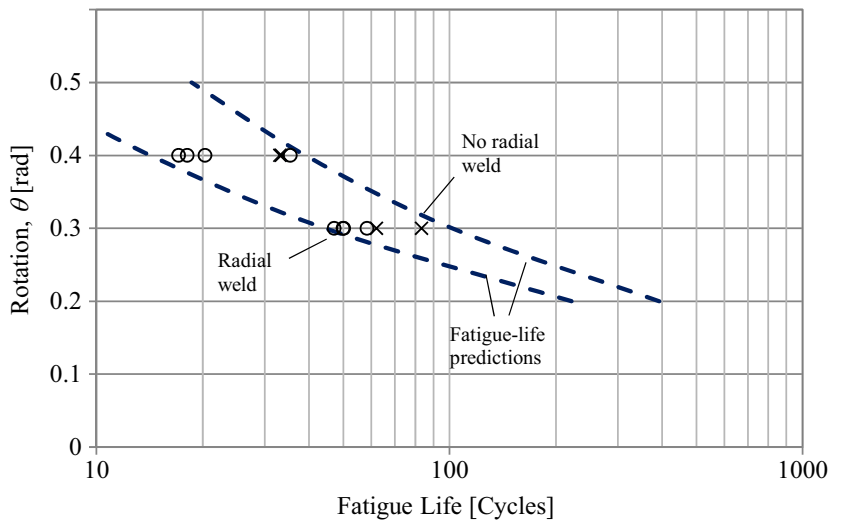

Fig. 9. Predicted versus measured fatigue-life for specimens with and without radial baseplate welds. 


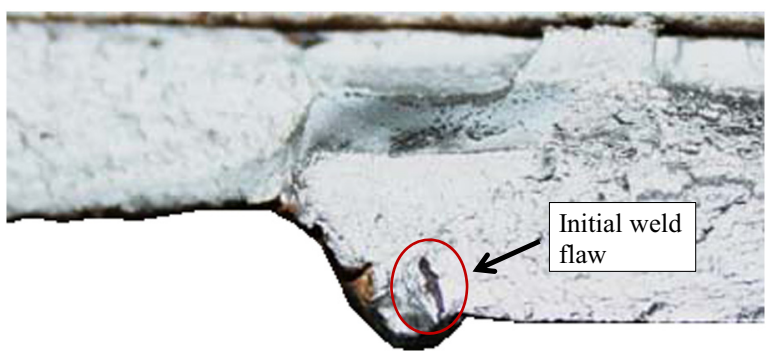

Fig. 10. Fracture surface near radial weld with initial radial weld flaw not propagated after cyclic loading.

specimens without radial welds, the fracture strain of the base material is assumed; for specimens with radial welds, the fracture strain of the weld material is used.

For specimens without radial welds, having a mean fracture strain (minus one standard deviation), $\mu_{\varepsilon f}-\sigma$, equal to 0.30 and base-plate thickness of $12 \mathrm{~mm}$, Eq. (1) predicts failure after 87.6 cycles and 32.6 cycles for $0.3 \mathrm{rad}$ and 0.4 rad respectively. For specimens with radial welds, having a minimum fracture strain equal to 0.219 and baseplate thickness of $12 \mathrm{~mm}$, Eq. (1) predicts failure after 44 cycles and 14 cycles for $0.3 \mathrm{rad}$ and 0.4 rad respectively. The minimum $\varepsilon_{f}$, not $\mu_{\varepsilon f}-\sigma$, was used for the weld specimens because only two valid weld specimens were tested.

When comparing predicted fatigue life with measured fatigue life in Table 4, the predicted values correspond well with measured values, even though the equation was not calibrated to $12 \mathrm{~mm}$ plates. Fig. 9 plots the predicted and measured fatigue life values for the specimens

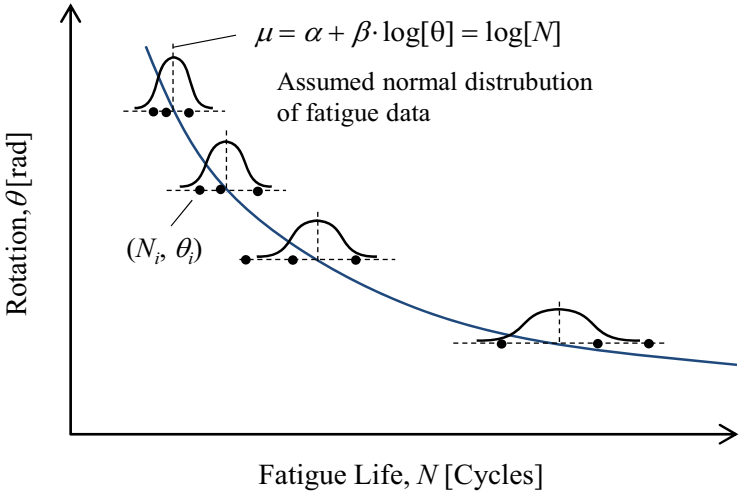

Fig. 13. Fatigue-life curve representation through MLE fitting.

with and without radial welds. Predicted values for the radial weld specimens (assuming the minimum measured weld ductility) were within 8 cycles of the mean measured failure cycle value at all rotation levels. Predicted values for the non-radial weld specimens were within 1 cycle of the mean measured failure cycle value at $0.4 \mathrm{rad}$ and within 15 cycles at 0.3 rad.

\subsection{Effect of radial welds on connection rotation capacity}

Tank connections containing radial welds have reduced fatigue-life compared to equivalent connections without radial welds. Connections with radial welds achieved nearly $30 \%$ less fatigue life at 0.4 rad and $0.3 \mathrm{rad}$ rotations, on average, when compared to equivalent connections

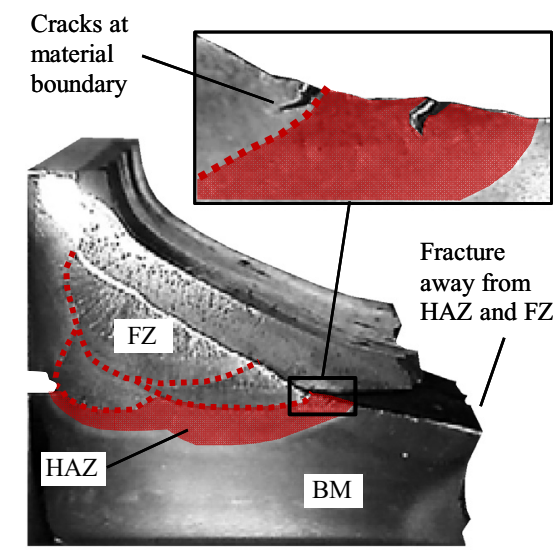

Specimen A5

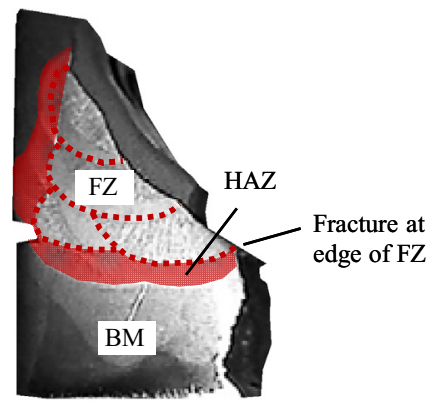

Specimen $A 4$

Fig. 11. Shell-to-base weld features (FZ, BM, and HAZ) and fracture locations for Specimens A4 and A5.
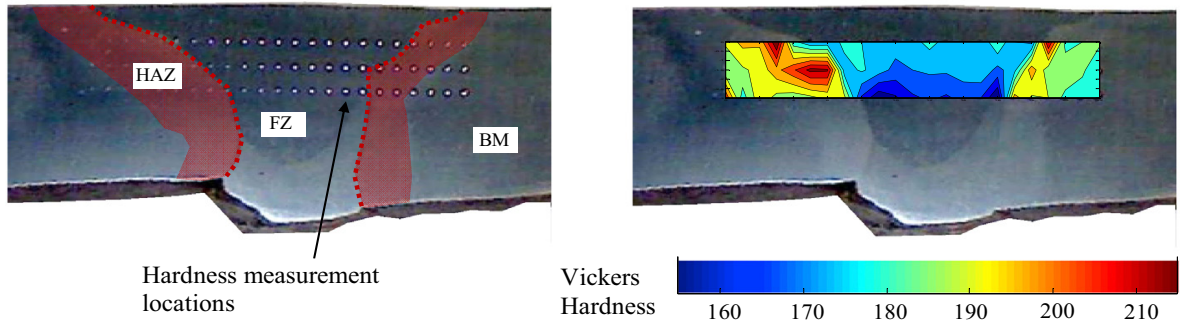

Fig. 12. Radial weld features (FZ, BM, and HAZ) taken near fracture surface, and Vickers hardness measurement contours (Specimen A5). 
without radial welds. This reduction in fatigue life can be directly associated with a ductility decrease in the weld and weld-HAZ of the radial weld region. Given only the lower ductility of the weld metal compared with the base metal, Eq. (1) (calibrated for connections without radial welds) was able to reasonably predict the fatigue-life of specimens having radial welds.

Even with nearly $30 \%$ reduction in fatigue-life, the capacity of all connections having radial welds far exceeded the current Eurocode 0.2 rad rotation limit. The lowest measured connection capacity, corresponding to a $12 \mathrm{~mm}$ base-plate containing a radial weld, achieved over 17 cycles at 0.4 rad prior to connection failure. Additionally, using the verified Eq. (1), and considering a $12 \mathrm{~mm}$ base-plate with the code lower-bound ductility requirement of 0.15 , the connection would still be expected to achieve nearly 6 cycles at 0.4 rad of rotation.

\subsection{Influence of initial weld flaws on damage evolution}

Initial fractures and flaws originating near the root of the radial welds appear to have negligible influence on the rotation capacity of the tank connections. Running parallel to the radial welds (perpendicular to the critical fracture), such fractures and flaws do not appear to progress through the base-plate thickness during cyclic loading (see Fig. 10).

\subsection{Metallographic analysis near transverse and radial weld fracture regions}

Critical fracture locations for the tank specimens varied between the transverse weld toe and several millimeters away from the transverse weld toe. Fig. 11 shows polished transverse weld regions for Specimen A4 (having fractured at the weld toe) and Specimen A5 (having fractured away from the weld toe and weld HAZ). While several smaller cracks are observable at the weld toe of Specimen A5, the critical crack forms several millimeters away, outside the HAZ (identified in Fig. 11 through metallographic analysis). It is still unclear what causes some specimens to fail away from the weld toe, however preliminary tests conducted on T-joint specimens having homogenous material properties and machined weld geometries suggest that the weld material and HAZ play a role. A preliminary T-joint test, having a machined weld geometry and homogeneous material properties, failed at the weld toe (near the geometric stress riser) matching predictions from finite element models in [9].

Fig. 12 shows a section of radial weld taken from Specimen A5. In Fig. 12, the various weld material zones are identified (FZ, BM, and HAZ) and hardness contours are plotted across the different regions. As expected, the hardness varies across the radial weld region, with the hardness in the HAZ outside the FZ being higher, indicating lower ductility. This HAZ for the radial welds runs perpendicular to the critical crack path and extends the entire length of the base-plate, creating a region of lower ductility for ULCF cracks to originate. This somewhat explains the observation that specimens with radial welds fail sooner than specimens without radial welds.

\subsection{Alternative creation of fatigue-life curves using maximum likelihood estimation}

In the previous studies $[7,8]$, and in the previous sections of this paper, fatigue-life curves are created using a simplified least-squares fitting procedure, minimizing the error between each data point and the regression line. In this section, an alternative curve creation approach is compared wherein an advanced statistical method called maximum likelihood estimation (MLE) is used to create fatigue-life curves that maximize the observed sample joint probability. The following paragraphs describe the MLE method and apply it to the tank fatigue data from this study (along with data from the previous tank studies [7, 8]). Comparisons are made between the fatigue-life curves generated
Table 5

Fatigue test data from Cortes et al. [7], Prinz and Nussbaumer [8], and the current study.

\begin{tabular}{|c|c|c|c|}
\hline$\theta[\mathrm{rad}]$ & Material grade & $\mathrm{N}$ & $\mu$ \\
\hline \multicolumn{4}{|c|}{ Cortes et al. [7] $(t=6 \mathrm{~mm})$} \\
\hline 0.4 & S355 & 22.1 & \multirow[t]{2}{*}{22.6} \\
\hline 0.4 & S355 & 23.1 & \\
\hline 0.3 & S355 & 96.5 & \multirow[t]{2}{*}{92.9} \\
\hline 0.3 & S355 & 89.3 & \\
\hline 0.2 & S355 & 430 & \multirow[t]{2}{*}{420.5} \\
\hline 0.2 & S355 & 411 & \\
\hline \multicolumn{4}{|c|}{ Prinz and Nussbaumer [8] ( $t=6 \mathrm{~mm})$} \\
\hline 0.5 & S355 & 59 & \multirow[t]{5}{*}{64.2} \\
\hline 0.5 & S355 & 67 & \\
\hline 0.5 & S355 & 73 & \\
\hline 0.5 & S355 & 60 & \\
\hline 0.5 & S355 & 62 & \\
\hline 0.4 & S355 & 132 & \multirow[t]{3}{*}{137} \\
\hline 0.4 & S355 & 125 & \\
\hline 0.4 & S355 & 154 & \\
\hline 0.3 & S355 & 306 & 293.3 \\
\hline 0.3 & S355 & 310 & \\
\hline 0.3 & S355 & 264 & \\
\hline \multicolumn{4}{|c|}{ Current study $(t=12 \mathrm{~mm})$} \\
\hline $0.4^{\mathrm{a}}$ & S355 & 34 & - \\
\hline $0.4^{\mathrm{b}}$ & S355 & 17.1 & \multirow[t]{4}{*}{22.7} \\
\hline $0.4^{\mathrm{b}}$ & S355 & 18.1 & \\
\hline $0.4^{\mathrm{b}}$ & S355 & 35.4 & \\
\hline $0.4^{\mathrm{b}}$ & S355 & 20.3 & \\
\hline 0.4 & S355 & 33.1 & \multirow[t]{2}{*}{33.3} \\
\hline 0.4 & S355 & 33.5 & \\
\hline $0.3^{\mathrm{b}}$ & S355 & 58.4 & \multirow[t]{4}{*}{$\overline{51.5}$} \\
\hline $0.3^{\mathrm{b}}$ & S355 & 50.0 & \\
\hline $0.3^{\mathrm{b}}$ & S355 & 50.2 & \\
\hline $0.3^{\mathrm{b}}$ & S355 & 47.2 & \\
\hline 0.3 & S355 & 83.4 & \multirow[t]{2}{*}{72.8} \\
\hline 0.3 & S355 & 62.2 & \\
\hline
\end{tabular}

a Geometry control specimen $(\mathrm{t}=10 \mathrm{~mm}$ ) from Phase- 1 testing ( $\mathrm{N}$ value neglected from fatigue-life curves).

b Specimens containing radial welds.

by least-squares fitting and MLE fitting and updates are given on tank connection rotation capacity.

\subsection{Overview and application of the MLE method}

The MLE method is summarized in four general steps: 1) propose a model and set of parameters that represent the observed data; 2) calculate the probability of having failure at each data point given an assumed set distribution; 3 ) calculate the joint probability accounting for all data points; and 4) determine the parameters from step 1 that maximize the joint probability of step 3 .

Based on previous low-cycle fatigue studies [10,11], a power-law relationship is assumed for each fatigue data set, given by Eq. (2):

$\log N_{f}=\alpha+\beta \log (\theta)$

Table 6

Proposed fatigue-life curve parameters obtained from MLE.

\begin{tabular}{lcc}
\hline & $\alpha$ & $\beta$ \\
\hline Phase-1 & -0.216 & -3.89 \\
Phase-2 & 2.26 & -2.85 \\
Phase-3 $^{\text {Phase-3 }}$ & 2.76 & -2.72 \\
& 1.68 & -2.84 \\
\hline
\end{tabular}

a Specimens with radial welds. 
where $N$ is the number of cycles to failure at a given applied constant rotation range, $\theta$. Parameters $\alpha$ and $\beta$ are unknown, to be determined through the MLE procedure. Fig. 13 shows the MLE based model assuming the above power-law relationship and considering $N$ as a normally distributed random variable at each rotation level.

The probability of having failure at each data point $\left(N_{i}, \theta_{i}\right)$ in Fig. 13 , assuming the data at each rotation level is normally distributed, is given by the probability density function:

$f_{N_{i}}=P D F_{N_{i}, \theta_{i}}=\left(\frac{1}{\sqrt{2 \pi \cdot \sigma}}\right) \exp \left(\frac{-1}{2 \sigma^{2}} \cdot\left[N_{i}-e^{\alpha}\left(\theta_{i}\right)^{\beta}\right]^{2}\right)$.

In Eq. (3), the standard deviation is assumed to vary by stress level $(\sigma=C / \theta)$ to account for an assumed linear increase in fatigue data scatter with decreased rotation range. This linear increase in $\sigma$ is based on the failures of $6 \mathrm{~mm} \mathrm{S355}$ base-plates loaded at $0.3,0.4$, and $0.5 \mathrm{rad}$ in [8].

The goal of the MLE is to maximize the joint probability of predicting failure at all points (or in other words, to maximize the likelihood of predicting failure at all points). This joint failure probability (or likelihood) is simply the product of every data-point failure probability, written as:

$L=\prod_{i=1}^{n} f_{N_{i}}$

where, $L, f_{N i}$, and $n$ are the likelihood, probability of predicting failure at an individual data point $(i)$, and the total number of data-points respectively. A nonlinear generalized reduced gradient optimization algorithm is used to maximize the likelihood given by the above MLE procedure.

Table 5 shows the sample fatigue data from each study and Table 6 shows the resulting optimized fatigue-life curve parameters $(\alpha, \beta)$ determined from MLE (to be used in Eq. (2)).

\subsection{Comparison between least-squares and MLE curves}

Fig. 14 shows the fatigue-life curves, distribution of fatigue data at each rotation level, and curve equations considering MLE and leastsquares fitting for each phase of testing. From Fig. 14, the MLE fatigue-life curve consistently predicts higher fatigue life at higher rotation amplitudes, compared to the least squares fit curve; however, predicted values are still close (MLE predicts 129.9 cycles at $0.4 \mathrm{rad}$ while least-squares predicts 127.6 cycles at $0.4 \mathrm{rad})$. See the table given in Fig. 14 for comparisons between MLE and leastsquares prediction for all rotation levels and fatigue data sets.

While the MLE curve predicts slightly higher fatigue-life at the higher rotation ranges, compared to the least-squares fitting approach, it has a higher statistical likelihood of predicting the measured fatigue data at each rotation range. For example, the likelihood of predicting the measured values (at 0.4 rad from test data gathered by Cortes et al.) using the MLE and least-squares fit equations is $1.307 \times 10^{-9}$ and $7.184 \times 10^{-13}$ respectively; which means the MLE equation is nearly 2000 times more likely to arrive at the measured fatigue values than the least-squares fit equation.

Note that at 0.4 rad of rotation, the expected fatigue capacity from the MLE fit curve is nearly 23 cycles for tank connections containing radial welds. Even with reduced capacity due the radial welds (compared to tank connections without radial welds), the expected fatigue life is significantly higher than the current code limit of $0.2 \mathrm{rad}$.

\subsection{Consideration of confidence level for safety evaluation}

Fatigue test results include variability, as evidenced by the normal distributions at each rotation level. To account for variability in the governing MLE fatigue-life curve (the curve from the data containing (a)

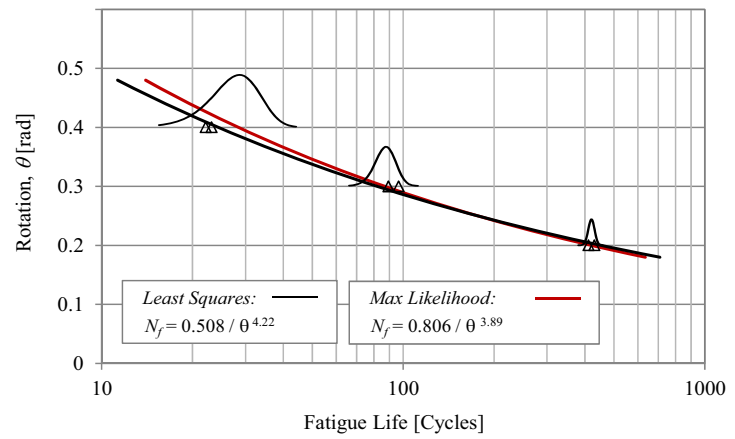

(c)

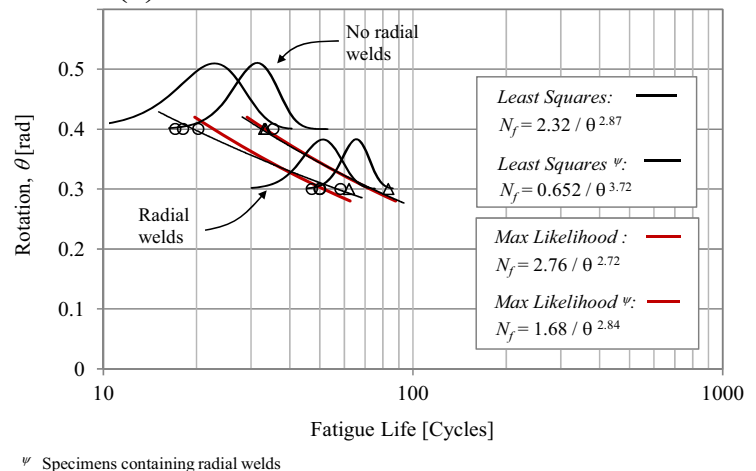

(b)

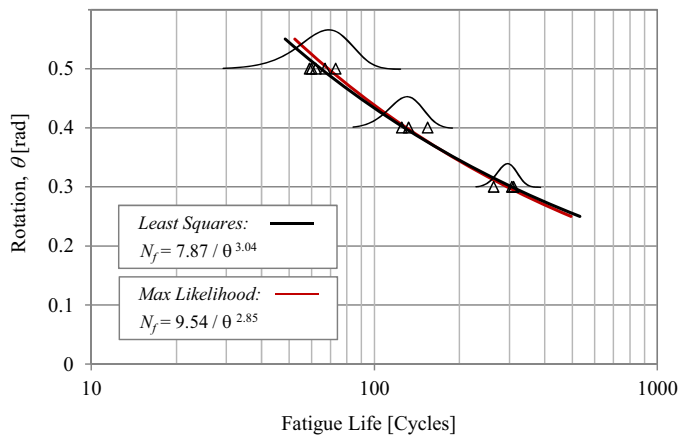

\begin{tabular}{lcccc} 
& \multicolumn{4}{c}{ MLE / LS } \\
\hline$\theta$ & Phase 1 & Phase 2 & Phase 3 & Phase 3 \\
\hline 0.2 & 0.93 & -- & -- & -- \\
0.3 & 1.07 & 0.96 & 0.99 & 0.89 \\
0.4 & 1.17 & 1.02 & 1.04 & 1.15 \\
0.5 & -- & 1.06 & -- & -- \\
\hline${ }^{a}$ MLE fit prediction normalized by least-squares prediction \\
${ }^{\psi}$ Specimens containing radial welds
\end{tabular}

Fig. 14. Comparison between MLE and least-squares fatigue life curve fits for: a) Cortes et al. [7], b) Prinz and Nussbaumer [8], and c) present study. 


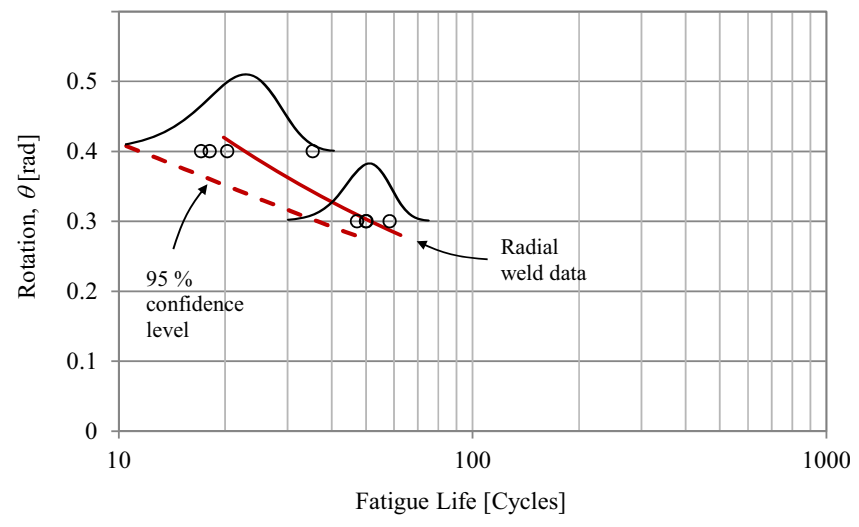

Fig. 15. 95\% confidence level curve from MLE curve (test data containing radial base-plate welds).

radial welds) a lower-bound 95\% confidence level is adopted to provide safety in the determination of fatigue life for welded tank connections. Fig. 15 shows the MLE curve representing a 50\% failure probability and the shifted MLE curve representing the lower-bound 95\% confidence level. From the lower-bound curve in Fig. 15, the shell-to-base connections having a $12 \mathrm{~mm}$ base-plate and radial welds would still withstand nearly 12 cycles at 0.4 rad of rotation. This suggests that the current code limit is overly conservative in its value of $0.2 \mathrm{rad}$.

\section{Summary and conclusions}

Twelve tank shell-to-base connections, with and without radial welds in the base-plate, were tested under constant amplitude rotation cycles to determine the low-cycle fatigue performance. All connection specimens were taken from existing tanks within Switzerland, having a $12 \mathrm{~mm}$ base-plate thickness and $160 \mathrm{~mm}$ base-plate width. Applied rotation ranges of $0.3 \mathrm{rad}$ and $0.4 \mathrm{rad}$ were chosen to investigate demands greater than current Eurocode limits. Biaxial loading (simultaneous application of base-plate tension and rotation) was used to simulate realistic tank demands such as base-plate membrane action during uplift. Statistical analyses were performed on the new fatigue test data and data from previous studies.

The following conclusions are based on the cyclic testing of the twelve tank connections with and without radial welds in the baseplate. Experimental testing indicates:

1) Tank base-plate sections containing radial welds govern the shellto-base rotation capacity during uplift. The rotation capacity (fatigue life) of tank shell-to-base connections containing radial welds was nearly $30 \%$ lower (on average) than equivalent connections without radial welds.
2) Even though capacity is reduced for connections having radial welds, the available capacity is still far greater than current code limits. Using the fatigue-life curve generated by maximizing the experimental sample likelihood (shifted by $2 \sigma$ to represent the lowerbound $95 \%$ confidence level), connections with radial welds could be expected to withstand nearly 12 cycles at 0.4 rad of rotation (two times the current Eurocode limit). From Cortes et al. [12], the largest expected cyclic demand for Switzerland (normalized by peak rotation) is 4 cycles and the current code limit appears overly conservative.

3) Initial radial weld defects (originating near the weld root, against the backing bar) appear to have little-to-no effect on connection rotation capacity. Such flaws or defects run perpendicular to the critical crack and were not observed to propagate through the thickness during testing.

4) The fatigue life equation proposed by Prinz and Nussbaumer [8] can reasonably predict the performance of base-plate connections having radial welds, given the ductility of the material within the weld region. Additionally, the equation reduction factor for plates thicker than $6 \mathrm{~mm}$ appears to be reasonable for the $12 \mathrm{~mm}$ plates in this study. Given this predictability, and considering the lower-bound ductility permissible in the current standards $\left(\varepsilon_{f}=0.15\right)$, a $12 \mathrm{~mm}$ plate at $0.4 \mathrm{rad}$ of rotation could be expected to achieve nearly 6 cycles before fatigue failure.

\section{References}

[1] Peek R. Analysis of unanchored liquid storage tanks under lateral loads. Earthq Eng Struct Dyn 1988;16:1087-100.

[2] Malhotra PK, Veletsos AS, Tang HT. Seismic response of unanchored liquid storage tanks. Proc. Structural Mechanics in Reactor Technology Conference (SMiRT-12). Suttgart, Germany. Paper No. SD103/101; 1993.

[3] Peek R, Jennings PC. Simplified analysis of unanchored tanks. Earthq Eng Struct Dyn 1988;16:1073-85.

[4] Malhotra PK, Veletsos AS. Uplifting analysis of base plates in cylindrical tanks. J Struct Eng 1994;120(12):3489-505.

[5] Fujikazu S, Akira I, Hajime H, Yukio M. Experimental study on uplifting behavior of flat-based liquid storage tanks without anchors. Proc. 9th World Conference on Earthquake Engineering., Tokyo-Kyoto, Japan; 1988. p. 649-54.

[6] Eurocode_8. Part 4: silos, tanks, and pipelines. ENV 1998-4. Brussels, Belgium: European Committee for Standardization; 1998.

[7] Cortes G, Nussbaumer A, Berger C, Lattion E. Experimental determination of the rotational capacity of wall-to-base connections in storage tanks. J Constr Steel Res 2011;67(2011):1174-84.

[8] Prinz GS, Nussbaumer A. On the low-cycle fatigue capacity of unanchored steel liquid storage-tank shell-to-base connections. Bull Earthq Eng 2012;10(6):1943-58.

[9] Prinz GS, Nussbaumer A. Fatigue analysis of liquid-storage tank shell-to-base connections under multi-axial loading. Eng Struct 2012;40:75-82.

[10] Coffin Jr LF. A study of the effects of cyclic thermal stresses in ductile metals. ASME 1954;76:931-50.

[11] Manson SS. Behavior of materials under conditions of thermal stress. Technical note 2933. Tennessee (USA): National Advisory Committee for Aeronautics; 1954.

[12] Cortes G, Prinz GS, Nussbaumer A, Koller M. Cyclic demand at the shell-bottom connection of unanchored steel tanks. 15th World Conference on Earthquake Engineering. Lisbon, Portugal. Paper No. 1115; 2012. 